Revista Eletrônica do Mestrado em Educação Ambiental

Revista do PPGEA/FURG-RS

ISSN $1517-1256$

Programa de Pós-Graduação em Educação Ambienta1

\title{
Narrativas de ressignificação: o processo dialógico na produção audiovisual com moradores de rua no centro do Rio de Janeiro
}

\author{
Mailsa Carla Pinto Passos ${ }^{1}$ \\ Universidade do Estado do Rio de Janeiro \\ https://orcid.org/0000-0003-1204-4505 \\ Jean-Christophe Houzel ${ }^{2}$ \\ Universidade Federal do Rio de Janeiro \\ https://orcid.org/0000-0001-5128-438x
}

Resumo: Este artigo narra a experiência de produção de um documentário sobre pessoas em situação de rua na Cidade do Rio de Janeiro. Em 2018, encontramos grupos de pessoas instaladas nas calçadas, sob as marquises das principais avenidas do Centro. Entrevistamos três famílias que se tornaram protagonistas do filme, atualmente em fase de montagem. Ao longo dos vários encontros com estas pessoas, na escuta dos relatos, na captura das imagens, emergiram entrecruzamentos de histórias e memórias. Essa construção de um diálogo no processo de produção audiovisual, com interlocutores historicamente silenciados e invisibilizados, promoveu questionamentos por parte dos realizadores, uma desconstrução dos estereótipos que fundamentam nossa percepção dos conceitos de família, casa, direitos e realidades, em um outro cotidiano ao mesmo tempo próximo e distante, tão perto, tão longe.

Palavras-chave: população em situação de rua, cotidiano, produção de não-existência.

\section{Narrativas de resignificación: el proceso dialógico en la producción audiovisual con personas sin techo en el centro de río de janeiro}

Resumen: Este artículo narra la experiencia de producción de un documental sobre personas en situación de calle en la ciudad de Rio de Janeiro. En 2018, encontramos grupos de personas instalados en las veredas debajo de los aleros de edificios de las principales avenidas del Centro. Entrevistamos a tres familias que se convirtieron en los protagonistas del documental, actualmente

\footnotetext{
${ }^{1}$ Professora Associada da Faculdade de Educação da UERJ, graduada em Letras, Mestre em Educação pela UERJ, Doutora em Educação pela PUC-Rio, Área Currículo e Cotidiano. E-mail: mailsappassos@ gmail.com

${ }^{2}$ Graduado em Biologia Celular e Fisiologia (Rennes), mestre em Neurofisiologia (Paris), PhD em Neurociências (Paris, 1995) com sanduíche no Institut d'Anatomie (Lausanne), e pós-doc no Max-Planck Institut für Hirnforschung (Frankfurt). É Professor de neurociências e diretor adjunto de Extensão do Instituto de Ciências Biomédicas da UFRJ. Email: jchouzel@gmail.com
}

Rev. Eletrônica Mestr. Educ. Ambient. Rio Grande, Dossiê temático "Imagens: resistências e criações cotidianas", p.411-429, jun. 2020. E-ISSN 1517-1256 
en fase de edición. A lo largo de varios encuentros con estos grupos, escuchando los relatos, capturando las imágenes, surgieron entrecruzamiento de historias y memorias. Esta construcción de un diálogo en el proceso de producción, con interlocutores históricamente silenciados e invisibilizados, promovió un cuestionamiento por parte de los realizadores, una deconstrucción de los estereotipos que fundamentan nuestra percepción de los conceptos de familia, casa, derechos y realidades en un cotidiano que es al mismo tiempo próximo y distante.

Palabras clave: población en situación de calle, cotidiano, producción de no existencia.

\title{
Narratives about resignification: dialogical processes during audiovisual production
}

\section{with homeless families in downtown rio de janeiro}

\begin{abstract}
We report the experience of producing a documentary about homeless people living on the streets of Rio de Janeiro, Brazil. In 2018, a growing number of people settled down on the sidewalks, under the concrete awnings of the main avenues of the Center. We interviewed three "families" who became protagonists of the movie, currently in the editing phase. Throughout several encounters with these people, while listening to their reports and recording their images, stories and memories started intertwining. Establishing such a dialog, within the audiovisual production process, with historically silenced and invisibilized interlocutors, urged the filmmakers to question themselves, and to deconstruct some of the stereotypes underlying their understanding of concepts such as family, home, rights, or realities of another daily life, so close and yet so far.
\end{abstract}

Keywords: homeless people, daily life, production of nonexistence.

\section{Surge um projeto a partir do crescimento das populações de rua na cidade.}

Ver, olhar, descrever o que se oferece a nós (...) Permanecer mais perto do real, em especial quando nos surpreende, quando ele não expressa docilmente o que estamos prontos para pensar. Sylvain Maresca

Em 2018, a população em situação de rua no Rio de Janeiro começou a crescer vertiginosamente, tanto devido à precarização e ao empobrecimento da população trabalhadora de modo geral, quanto em função das alterações nas políticas públicas de assistência aos mais necessitados e desfavorecidos, que sofreram cortes drásticos e reorientações ideológicas e estruturais profundas pelos governos das esferas municipais, estaduais e federais, eleitos democraticamente com base em um discurso que prometia cuidar dos cidadãos e salvar a pátria e a economia, discurso este repetido diariamente pela imprensa hegemônica.

Mídia essa que, alternando narrativas sobre os trâmites judiciários das reformas trabalhistas ou tributárias, com relatos diários das elucubrações das personagens de um governo hiper-conectado nas mídias não-oficiais - mas com profundo descaso com a realidade do povo brasileiro - ou ainda investindo em pautas sensacionalistas envolvendo famosos, corrupção ou violência urbana, demostrou, como tem sido praxe na segunda metade desta década, um desinteresse absoluto tanto pelos mais pobres quanto pela 
população de rua que vem crescendo ao passo que é cada vez mais desprovida de direitos e de existência social.

Mobilizados por três fatores distintos, porém complementares, decidimos conversar com pessoas em situação de rua e filmar esses encontros. O primeiro motivo foi nosso espanto ao constatar o aumento das pessoas que encontrávamos nessa condição ${ }^{3}$ ao passar pelas ruas do Centro. A segunda motivação foi a percepção de que não se sabia nem se comentava nada a respeito desses grupos de moradores instalados nas calçadas das principais avenidas, abrigados pelas largas marquises de instituições públicas, centros comerciais, ou espaços de cultura, movimentados durante o dia e desertos à noite, a não ser por esta população. O terceiro motivo, bastante ambicioso, foi uma tentativa de contribuir para dirimir preconceitos em relação a essas pessoas: seguimos buscando uma maneira de adentrar esse universo desconhecido, para compreender um pouco mais tanto a condição atual dessas pessoas, quanto a sua trajetória, seus percursos e seus percalços.

Certeau (1994) já chamava nossa atenção para o fato de que ver a cidade - e vivê-la - do alto de um grande edifício, de seu terraço, é uma experiência muito distinta daquela que é andar por suas ruas. Ele escreve: "a cidade-panorama é um simulacro teórico" (op. cit. p. 171), que desconhece as práticas cotidianas e que "esconde" seus praticantes. É caminhar pelas ruas da cidade grande, tanto pelas largas avenidas como pelas ruazinhas pouco iluminadas, que faz nossa inútil tentativa de tomar um olhar totalizante sobre a cidade, converter-se em uma experiência de reinventá-la, na medida em que a ocupamos. Caminhar pela cidade é inventar caminhos, inventariar histórias, dialogar com o espaço, ocupá-lo e enunciá-lo.

Para entender essas enunciações, que são marcas deixadas por nós no espaço urbano, mais ainda, para compreender o cotidiano do espaço urbano, precisamos primeiramente estranhá-lo. Mesmo que caminhemos por aquela rua com frequência, mesmo que encontremos as pessoas que circulam por ali diariamente, é preciso se permitir desaprender aquilo que achávamos que sabíamos. É preciso deixar agir, para além da razão, a intuição: o saber antes que o entendamos como legítimo.

Ao rés do chão circulam os "praticantes do cotidiano" que caminham pela cidade e enunciam tais ações de ocupação, refletidas nos tempos e nos espaços.

A cidade-conceito - vista do alto e, ilusoriamente, como objeto do desejo de um conhecimento que a apreenda em sua totalidade - pode ser a cidade-degradação, que

\footnotetext{
${ }^{3} \mathrm{O}$ fato é que sempre houve população em situação de rua no Rio de Janeiro, mas seu número tendia a diminuir durante o precedente período de crescimento econômico e de governos populares.
}

Rev. Eletrônica Mestr. Educ. Ambient. Rio Grande, Dossiê temático "Imagens: resistências e criações cotidianas", p.411-429, jun. 2020. E-ISSN 1517-1256 
"talvez se esteja deteriorando ao mesmo tempo em que os procedimentos que a organizaram" (CERTEAU, 1994, p. 174). Já a cidade como experiência cotidiana é outra. Seria aquela na qual ao mesmo tempo em que a linguagem do poder se urbaniza, é reinventada por pessoas comuns do espaço/tempo urbano. Pessoas que, com suas múltiplas formas de estar e ser no mundo, reinventam o espaço enquanto se ressignificam naquele processo de ocupação.

Este texto traz uma reflexão sobre o princípio dinâmico inerente ao processo criativo audiovisual, no que diz respeito especificamente à experiência de uma pequena equipe de produção, formada por estudantes de áreas diversas e professores da UERJ e da UFRJ, que decidiram fazer um filme relatando o cotidiano de alguns moradores das ruas do Centro da Cidade do Rio de Janeiro.

\section{Imagens e sons como elementos para compreender as relações dialógicas}

Bakhtin nos lembra que "as relações dialógicas, embora pertençam ao campo do discurso, não pertencem a um campo puramente linguístico" (BAKHTIN, 2008, p. 208). Elas são relações socias que se convertem em enunciados, que estão "fora da moldura do discurso", são da ordem do extralinguístico, mas é no discurso que se manifestam.

A produção de material audiovisual consistiu para nós assim na busca de compreender essas relações para além do discurso e do que estava sendo enunciado. A linguagem audiovisual foi escolhida como forma de encontro, expressividade e testemunho que nos dessem as pistas de como essas pessoas, seus desejos, gostos e pontos de vista relacionavam-se dialogicamente com a sociedade que os coloca neste absoluto não-lugar.

E ainda, surgiu da necessidade urgente de apresentarmos os rostos dos protagonistas, para que eles fossem reconhecidos primeiramente como sujeitos, e não como anônimos do coletivo "população de rua". Um outro aspecto, que julgamos essencial, era o de que as imagens fossem inteiramente gravadas nas próprias moradias dos protagonistas - ou nos espaços imediatamente vizinhos por eles ocupados -, evitando qualquer afastamento poético-estético do local dos seus cotidianos.

Desta forma, o filme-documentário irá mostrar cenas gravadas, sem muitos efeitos de iluminação, nem muitas movimentações da câmera, que poderiam distrair o espectador do foco das conversas ou atrapalhar seu encontro com as personagens. Recorremos ao travelling apenas para oferecer uma perspectiva mais ampla do contexto espacial dos fragmentos de calçadas, ou para abordar questões de vizinhança. Recorremos ao close 
apenas para seguir o olhar ou enquadrar as demais expressões não verbais que acompanham uma ou outra declaração com conteúdo emocional particularmente intenso. Assim, procuramos recriar - para o futuro espectador - a relativa intimidade das nossas conversas in loco.

Além das imagens, a linguagem audiovisual permite compartilhar a própria voz dos protagonistas, bem como o ambiente sonoro dos seus respectivos lares. Ao contrário de um texto escrito ou de um comentário narrado, o som original da voz do protagonista carrega o contexto emocional, cognitivo e subjetivo, o qual pode estar de acordo ou em dissonância com o conteúdo veiculado pelo significado objetivo das palavras. Novamente, nossa intenção não era de interpretar, mas sim de escutar e compartilhar as opiniões e os discursos.

"Falar é existir absolutamente para o outro" (FANON, 2008, p.33). Frente aos inúmeros preconceitos com as pessoas em situação de rua, nossa primeira intenção foi encontrar, descobrir, e colocarmo-nos na condição de uma escuta sensível em relação a esses sujeitos silenciados por uma sociedade consumista, na qual as pessoas são definidas pelos objetos/bens que possuem, consomem ou produzem.

Antes de tudo, queríamos escutá-los, para além do burburinho de vozes sem rostos e sem nomes, que é o que captamos, ao percorrer - apressados e inquietos -, o pedaço de calçada que é o lar deles. Não tínhamos perguntas especificas, nem seguimos um roteiro predeterminado: apenas nos colocamos interessados nos seus cotidianos e disponíveis, mobilizados por algumas questões gerais, tais como "Há quanto tempo estão morando aqui?"; "Você tem família?”; “Qual é o seu sonho?”; "Você gostaria de dizer ou mostrar algo?"; "Conte essa estória de novo para gente?". Perguntas gerais a partir das quais deixamos cada sujeito elaborar livremente sua própria narrativa, ou - quando fosse o caso - simplesmente não falar, manter-se em silêncio numa reflexão sem pressa, que poderia levá-lo a discursar sobre qualquer outro assunto. As entrevistas foram feitas em grupo pequenos, nunca individualmente

Desta forma, a linguagem audiovisual nos pareceu suficientemente potente tanto para fomentar a humanização de cada um dos protagonistas, como para alcançar ouvidos e olhos blindados por essa sociedade, na qual a existência dos sujeitos tem sido medida pela régua dos seus níveis de consumo. Uma sociedade que gestou um conjunto de seres humanos negados em seus saberes e suas lógicas, um mundo dividido por uma linha abissal imaginária, no qual quem está do outro lado da linha é produzido como "não- 
existência" (SANTOS, 2008). São, precisamente, esses sujeitos "não-existentes" que passamos a reparar nas calçadas e a escutar com atenção e tempo suas histórias.

\section{Três famílias sem teto, mas com endereço}

Conforme as escolhas justificadas acima, entrevistamos três "famílias" que morram nas ruas do Centro do Rio de Janeiro, e se tornaram protagonistas de um documentário, atualmente em fase de montagem.

\subsection{Glória, Alan, Alanzinho e Alana}

Conhecemos Alan - 35 anos - ao acompanhar um grupo de voluntários que distribuem refeições quentes e mantimentos básicos (itens de higiene, roupas) para populações de rua, operando um modo de rodizio mensal em uma meia dúzia de locais predeterminados no Centro.

Animado e bastante comunicativo, ele nos convidou a voltar após a distribuição para conhecer sua família, formada pela esposa Glória, o filho Alanzinho, de dois anos (um menino forte, saudável, curioso e afetuoso como qualquer criança da sua idade), e a recémchegada Alana, de três meses.

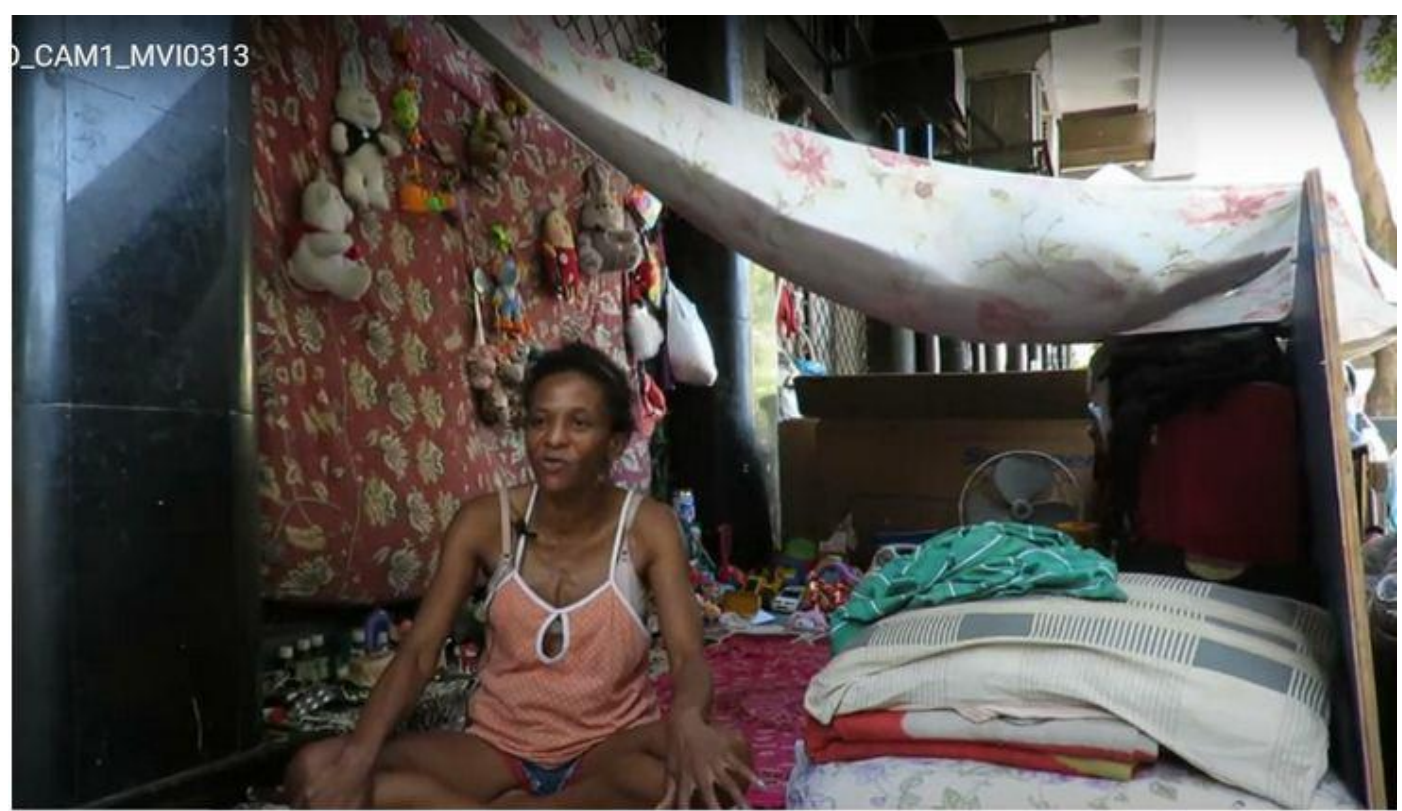

Figura 1: Gloria, na frente da sua casa, ao lado da sede da Ordem dos Advogados do Brasil. "Eu gosto de tudo arrumado, de deixar os brinquedos bem organizados. Quando Alan deixa a blusa dele assim, já fico agoniada. Quando ele toma banho e deixa a toalha pendurada, eu já reclamo."

Rev. Eletrônica Mestr. Educ. Ambient. Rio Grande, Dossiê temático "Imagens: resistências e criações cotidianas", p.411-429, jun. 2020. E-ISSN 1517-1256 
Assim que Alan nos viu chegando, ele veio ao nosso encontro, animado com a perspectiva de receber uma visita na sua casa, e - antes de tudo - orgulhoso de nos apresentar sua família.

Há três anos, eles vivem num espaço de $4 \times 2$ metros, na calçada em frente ao um restaurante, a poucos metros da sede da Ordem dos Advogados do Brasil (OAB-RJ). Protegidos por uma grande marquise, frente a uma vasta praça arborizada e muito tranquila - uma rua de mão única que serve como estacionamento, portanto com trânsito quase nulo e segurança 24 horas - eles montaram uma estrutura com portas de madeira, móveis recuperados e lonas.

Ali, eles têm acesso quase continuo à água, disponibilizada pelos funcionários do restaurante, que também oferecem eletricidade, via uma extensão, por algumas horas diárias, antes do encerramento do expediente, compartilhada com dois vizinhos de calçada: um instalado numa estrutura bem mais modesta, mas também com alguns apetrechos, carinhos para transportar mercadoria. O outro vizinho tem apenas caixas de papelão. Todos são residentes permanentes daquela esquina há alguns anos.

Glória termina de amamentar a filha, troca sua fralda, lhe faz um carinho e diz umas doces palavras maternas, antes de instalá-la confortavelmente no colo do pai: Agora bota ela para ninar e fique de olho no Alanzinho, que vou fazer as honras da casa. Sorridente, nos convida a apreciar o interior da sua casa. Embora exíguo, o espaço está arrumado com capricho e perfeitamente organizado: roupas de cama passadas e empilhadas, artigos de higiene e beleza alinhados, alguns remédios preservados nas suas caixas e, claro, dezenas de brinquedos, pendurados nas paredes da tenda que não tem nada de "improvisada". Ao longo de vários encontros e longas conversas, inclusive numa outra sessão de gravação realizada na praça das cercanias, onde as crianças podem brincar tranquilamente, e subir nas árvores com segurança, Glória e Alan nós contaram suas vidas: amargos e dramáticos na hora de contar experiências de violência, drogas e prostituição das suas vidas passadas; emocionados e divertidos ao lembrar de como se encontraram e se apaixonaram. Empoderados e reivindicativos ao contar seus valores e suas aspirações; chorando ao lembrar do fiel cachorro que teve que ser sacrificado, e que hoje foi substituído por um outro companheiro simpático, que se atrapalha nos cabos de som e luz do equipamento de filmagem. 


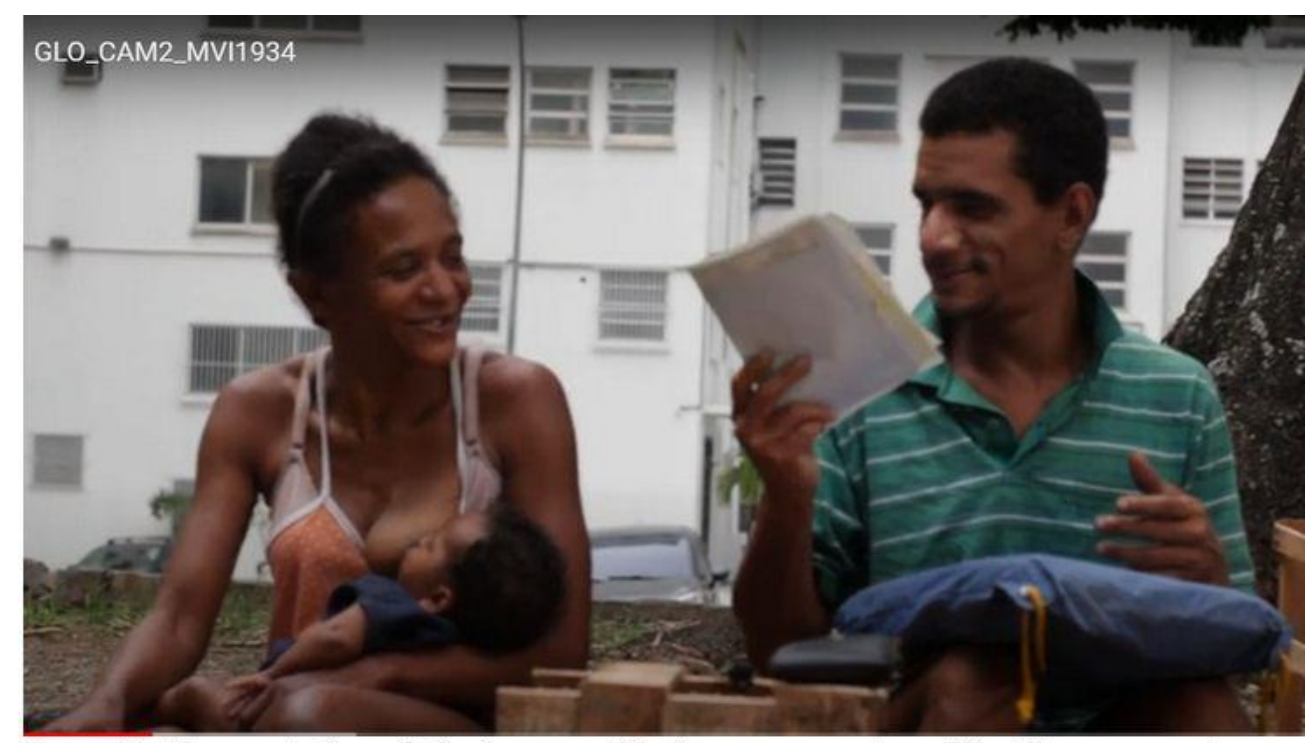

Figura 2: Alan, sentado ao lado da esposa Gloria que amamenta a filha Alana, apresenta seus documentos oficiais, guardados numa pasta. "Eu nunca trabalhei de carteia assinada, mas estou com o documento faz quase dois anos. A Gloria que me mandou tirar, quando o nosso Alanzinho nasceu. Quem sabe, um dia, eu consigo um emprego de verdade?"

Além das palavras e das histórias, das verdadeiras lições, sobre racismo, sexismo, organização do trabalho informal, ou ainda sobre educação escolar, Gloria e Alan fizeram questão de nos mostrar seus documentos: certidões de nascimentos, protocolos de pedidos de inserção em programas sociais, solicitação de emprego, todos eles organizados em uma pasta de plástico transparente. Gloria não sabe ler, mas sabe perfeitamente a importância e o significado de cada documento. Seu maior orgulho é que Alan ter registrado as crianças. Hoje eles formam hoje uma verdadeira família, digna. Uma família padrão: mãe, pai, um casal de crianças, uma casa, um cachorrinho no quintal.

\section{2- Dona Carla e seus dois netos}

Um outro grupo que encontramos, sob a marquise da Defensoria Pública, representa uma estrutura familiar menos tradicional, mas também uma configuração extremamente frequente no Brasil: composto pela Dona Carla e seus dois netos: Robson (9 anos) e Thais (4 anos). Durante a semana, eles moram em Belford Roxo, na Baixada Fluminense, onde têm uma casa, com quintal e animais de estimação. É lá também que as crianças estudam, todos os dias. Já que a mãe não tem condição de criar os filhos, é a avó que o faz, sendo beneficiária do Bolsa Família.

Toda sexta-feira, Dona Carla espera o neto voltar da escola, busca a neta na saída da creche e, no fim da tarde, pega o trem de Belford-Roxo até a Estação Central do Brasil. De lá, andam até a calçada da Defensoria, onde se instalam para dormir, num espaço já 
reservado entre outros moradores vizinhos. No sábado, acordam cedo e se deslocam para Botafogo, onde ela trabalha como vendedora ambulante de doces e guloseimas. Concentrase neste trabalho até domingo de noite, quando volta de trem para casa, para os netos não perderem a escola na segunda-feira. Dona Carla argumenta que não pode ir e voltar todos os dias para seu trabalho em Botafogo, pois o gasto com o transporte seria tão alto que não compensaria. Por isso, e para o bem estar e a educação das crianças, ela passa com eles os finais de semana na rua. Ela escolheu aquela marquise, pois lá vivem muitas outras famílias e trabalhadores que não têm domicilio fixo suficientemente próximo.

A questão do transporte "público" é crítica para a inclusão dos trabalhadores no espaço urbano. Ao longo das conversas, foi recorrente a narrativa de que a dificuldade de pagar os valores da condução influencia diretamente no fato das pessoas morarem nas ruas. É como se elas fossem empurradas para as calçadas.

A calçada de Defensoria Pública é, portanto, um ambiente familiar, onde todos os vizinhos se respeitam e onde Dona Carla sente que as crianças estão seguras, onde elas podem brincar, ler e estudar com calma e tranquilidade. Enquanto Robson brinca com meninos da vizinhança, e que Thais percorre os livros que trouxemos, seguindo com o dedo as letras enfileiradas que começam a fazer sentido, Dona Carla conta, com reserva e dignidade, como ela se surpreendeu quando a neta comentou sobre uma estátua de uma praça vizinha, como ela se emocionou com questionamentos sobre aquela obra de arte e sobre a representação de personagens famosas. Ela acredita que Tatá vai ser escritora, ou professora. O Robson é mais tímido, mas é um bom menino. Ele já não gosta tanto de ler, mas é aplicado, esforçado, e só tira notas boas.

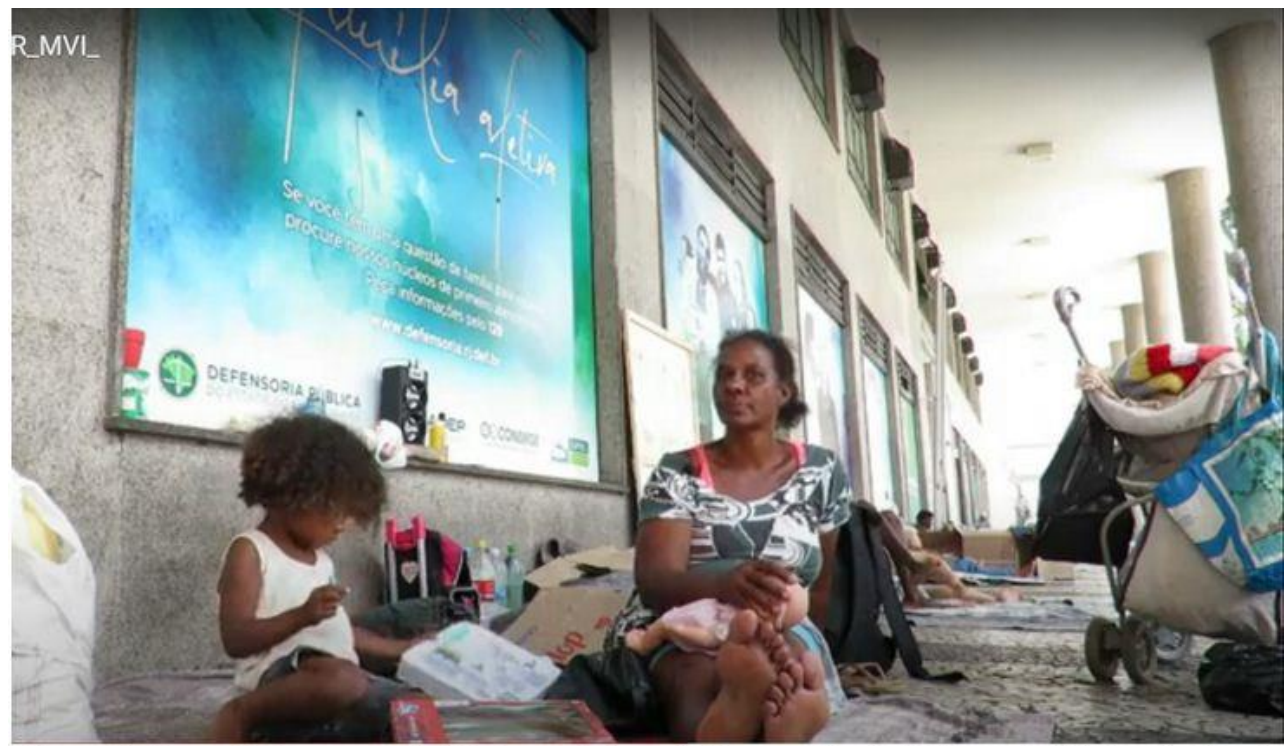

Figura 3: Dona Carla e sua neta Thais, sentadas sob da marquise da Defensoria Pública do Rio de Janeiro. "A Tatá gosta de livro, gosta muito de livros. Eu acredito que ela vai ser escritora, ou professora."

Rev. Eletrônica Mestr. Educ. Ambient. Rio Grande, Dossiê temático "Imagens: resistências e criações cotidianas", p.411-429, jun. 2020. E-ISSN 1517-1256 


\subsection{Bia, Fernanda e Paulo}

Ao passear pela Avenida Rio Branco, na altura do prédio do Centro Cultural da Caixa Econômica Federal, chama nossa atenção uma numeração feita com giz de cera colorido, no rodapé, ladeando os colchonetes enfileirados ao longo da parede, distribuída em espaços iguais: $101,102,103 \ldots$

Quando paramos para observar melhor, uma mulher trans, alta, muito bonita, puxa conversa, pergunta se não temos um dinheiro para ela comer. O diálogo segue. Bia tem 25 anos, brincalhona e educada. Ela está indo há algumas centenas de metros dali, no Largo da Carioca, tomar seu banho diário num espaço público, usado por todos os "moradores" da região. É sempre limpinho, mas às vezes tem fila. Bia nos apresenta seus vizinhos, Fernanda e Paulo, que morram no 103.

A conversa segue e, quando percebemos, estávamos sentados no colchão do número 102, num papo animado com os vizinhos contando seus casos.

Paramos ali, interpelados pela figura da Bia, mas também pela organização dos objetos dispostos com uma preocupação estética que, novamente, não enxergávamos ${ }^{4}$ no contexto da população de rua. O rodapé da parede da Caixa Econômica serve de prateleira para os pertences de Bia. Ali estão cuidadosamente dispostos seus esmaltes, seus livros literatura espírita e de autoajuda - sua maquiagem, e um pequeno rabo de sereia de plástico azul, abaixo da inscrição de giz "102". Um território definido, demarcado pela subjetividade e o gosto da dona do espaço.

Havíamos encontrado ali mais uma família de rua, mais um grupo de vizinhos com suas narrativas de conflitos e de solidariedade. Escutamos seus relatos de organizações familiares passadas, histórias de amor, de amizade, de decepção e de esperança, casos de vizinhança e "fofocas de bairro": Depois daquela banca de jornal, aí já é 'Zona Sul', a gente não se mistura com eles, cada um no seu quadrado e fica tudo certo, nos conta Bia.

\footnotetext{
${ }^{4}$ Quando utilizamos a palavra "enxergar" estamos nos referindo não ao nosso desejo de não ver, o que também poderia ser verdadeiro, em função da dor causada por esta visão, mas referimo-nos principalmente ao fato de que isso era produzido para nós como invisível.
}

Rev. Eletrônica Mestr. Educ. Ambient. Rio Grande, Dossiê temático "Imagens: resistências e criações cotidianas", p.411-429, jun. 2020. E-ISSN 1517-1256 


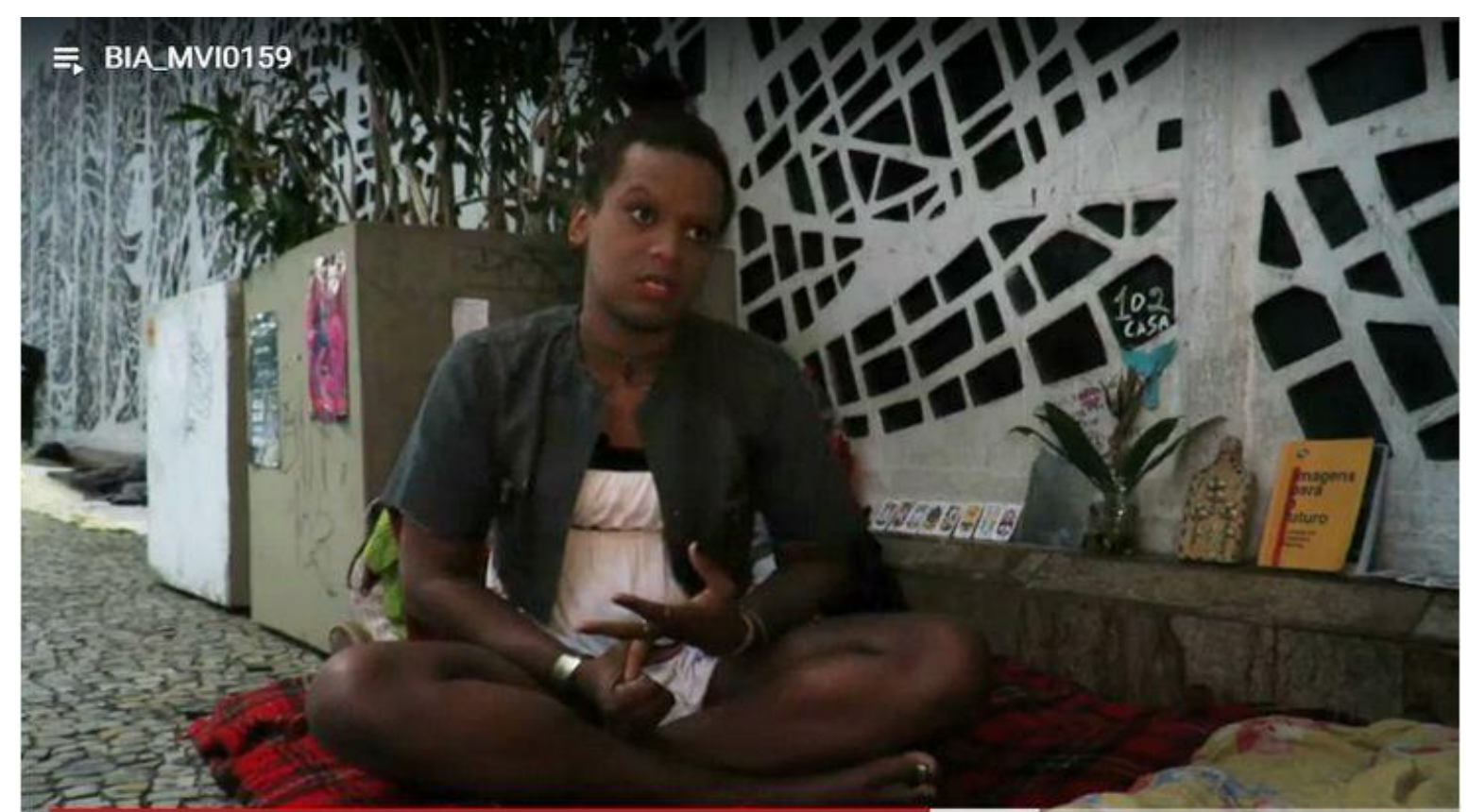

Figura 4: Bia, sentada no seu pedaço de calçada na frente do Espaço Cultural da Caixa Econômica Federal. "Olha, meu endereço é na Caixa, e o número é 102. Só procurar lá, tá escrito "Bia", que você vai achar. A Fernanda é no 103, tá escrito lá "Fernandinha e Paulo".

Quando terminamos a longa sessão de gravação, a noite já estava chegando estavam todos cansados de tanto falar e relembrar o dia que passamos. Paulo pediu um cigarro e se retirou para olhar suas mensagens e ver as notícias no celular. Fernanda pede para sua vizinha um espelho emprestado para se pentear, durante longos minutos, antes de se juntar ao companheiro e de fechar a cortina do 103, preservando assim sua privacidade. Bia "saiu" para conversar uns minutos com dois guardas municipais que já haviam passado mais cedo pela calçada, e comentaram amigavelmente Tá ficando famosa né, Bia? Após o estresse do longo dia, ela faz para eles um relato animado da filmagem com o pessoal da universidade. Enquanto gravamos algumas cenas de ambientação, juntamos o material, e organizamos o dia seguinte com os estudantes, Bia já está de volta no 102, deitada sobre seu colchão, está imersa na leitura de um livro.

Todos os protagonistas do filme surgiram de coincidências, ou errâncias, como nos orienta Certeau (1994), ou como nos lembra o ditado popular: "buscamos o que víamos e encontramos o que não víamos”. Encontramos pessoas que constituam famílias, sejam essas tradicionais, recompostas pelas vicissitudes da existência na cidade grande, ou reinventadas e solidificadas pelas amizades únicas de uma comunidade de destinos compartilhados. Talvez a ressignificação mais importante ocorrida com a equipe no processo de realização deste documentário seja oriunda do fato de que enquanto 
procurávamos por pessoas "sem teto" - consequentemente "sem-endereço" - descobrimos que todas elas tinham um endereço. Bia referia-se assim ao pedaço de calçada que ocupava, compartilhado com seus vizinhos; Dona Carla por sua vez possui um endereço fixo durante a semana em Belford Roxo, e outro na Defensoria nos sábados e domingos; Alan e Glória referem-se ao lugar que ocupam em frente ao restaurante e à Bolsa de Automóveis, também como seu endereço. No movimento das errâncias deslocamo-nos do lugar do preconceito e desconstruímos estereótipos. Isso inclusive nomeou o documentário. Podemos afirmar que foi o filme que encontrou seu nome no processo de produção. Chama-se "Endereço".

\section{Coexistir}

\subsection{Invisibilizados e silenciados pelas megalópoles.}

A condição de invisibilidade, mais do que isso, a não-existência de pessoas que compartilham conosco o espaço urbano, é uma construção. Construção que remete àquilo para que Santos nos chama a atenção: vivemos tempos de um pensamento abissal. Para o Santos (2010), vivemos:

[...] num sistema de distinções visíveis e invisíveis, sendo que as invisíveis fundamentam as visíveis. As distinções invisíveis são estabelecidas através de linhas radicais que dividem a realidade social em universos distintos: o universo 'deste lado da linha' e o universo 'do outro lado da linha. (SANTOS, 2010, p. 31)

O que está do outro lado da linha abissal é tornado inexistente, irrelevante. O pensamento abissal produz ignorância em relação a tudo que não está deste lado da linha, na medida que engendra uma ausência, um não existir. Santos (op. cit.) chama a nossa atenção ainda para o fato de que o campo do direito e do conhecimento modernos sustenta o pensamento abissal e lhe garante o sucesso. É ele que confere hegemonia à ciência moderna, e que determina quais conhecimentos são os falsos e quais são os verdadeiros. A visibilidade da ciência moderna se mantém a partir da invisibilidade de outras formas de conhecer: os saberes populares, os conhecimentos leigos, dos camponeses, das populações indígenas - historicamente deslegitimados em função do pensamento abissal. No que diz respeito ao direito moderno, a produção da não-existência corresponderia aos critérios que 
determinam aquilo que é legal ou ilegal. De um lado da linha: o campo do direito; e do outro lado: o não-direito, a inexistência jurídica.

É preciso lembrar sempre que, por trás dos conhecimentos, das práticas e das formas de legalidade, estão os sujeitos. Os moradores de rua, praticantes do cotidiano urbano, pertencem a grupos sociais que também são produzidos como não-existências, já que foram invisibilizados e negados como detentores de saberes, como sujeitos de direitos. Definidos por seus comportamentos incompreendidos pela sociedade "civilizada", os que não existem no mundo moderno, apenas por não terem aí um papel legitimado, seriam, no contexto do pensamento abissal, os "incivilizados".

"A humanidade moderna não se concebe sem uma sub-humanidade moderna" (SANTOS, 2010, p. 39). Ao fazermos o exercício de pensar esta definição de "humanidade" - vinculada à modernidade forjada dentro do sistema capitalista, que necessita de uma ordem. Aqueles que não detém os meios de produção nem os de consumo, estão do outro lado da linha da existência, fora da categoria humana: são eles os in-humanos, ou sub-humanos.

O projeto de produzir material audiovisual, registrando as narrativas e histórias de famílias em situação de rua, nos incentivou a problematizar este lugar da não-existência, da não-humanidade, do não-saber. Perguntamo-nos o que essas pessoas teriam a dizer sobre e para essa sociedade que os relegou ao lugar de não-existência? De que táticas $^{5}$ (CERTEAU, 1994) lançam mão cotidianamente para afirmar-se e existir em uma metrópole brasileira do século 21 ? Como coexistem neste mundo?

Ao longo das sessões de gravação, visualização e edição com a equipe de produção, também fomos, nós e os estudantes, reinventando maneiras de olhar e de escutar essas pessoas, de perceber as relações dialógicas estabelecidas por elas com a sociedade em que vivem, e ainda, de perceber quais atitudes responsivas essas pessoas assumem diante da sociedade para afirmarem sua existência. Fomos passando nós mesmos, por um processo de desconstrução dos nossos inúmeros estereótipos que, para Bhabha (1998), seriam frutos da repetição do discurso sobre o outro, colocando-o no lugar da fixidez, aquele modo de ver que aprisiona o sujeito-interlocutor no lugar da objetificação.

\subsection{A dinâmica dialógica na produção de narrativas audiovisuais}

\footnotetext{
${ }^{5}$ Para Certeau (1994) a tática é determinada pela ausência de poder, é a ação, a arte do mais fraco, aproveitando a ocasião
} 
Acreditamos na potência da produção audiovisual nas pesquisas em Ciências Humanas e Sociais, pela complexidade do instrumento de coleta, pela sua capacidade de gerar e preservar universos de memórias, simulações e ficções, e ainda como veículo de expressão de vozes silenciadas, emergentes ou esquecidas.

Há questões importantes em relação à dialogicidade da linguagem audiovisual. $\mathrm{O}$ que é de se esperar de uma linguagem privilegiada capaz, por exemplo no caso da sétima arte, de expandir a mente humana por além do espaço/tempo pessoal ou coletivo, real ou imaginário. Peixoto (2011, p. 32) nos diz que:

Se a transposição da experiência de campo para o texto científico é limitadora e monológica por natureza, o uso do audiovisual permite modificar a maneira como se relata tal experiência (desde que o pesquisador esteja comprometido a incluir outras vozes na etnografia), mas tampouco dá conta da descrição total de um fenômeno social.

Não são raras as transposições de experiências de encontro com o outro que são realizadas de maneira monológica - onde somente se torna visível a experiência do narrador-pesquisador. Entretanto, o audiovisual, permite uma aproximação sensorial bastante íntima com o protagonista: o filme visibiliza seu contexto, e "escutabiliza" sua fala, com toda sua prosódia carregada de significados explícitos e implícitos. Mesmo que o material "capturado" e gravado esteja sujeito a uma edição ou a uma roteirização, a tecnologia em si envolve uma dinâmica de coexistência perceptiva (ver e ouvir). E permite ainda que cada espectador, sujeito da recepção do produto projetado, multiplique um universo ampliado de percepções, atenções e intenções.

Algumas escolhas do realizador, intencionais ou improvisadas ao longo do processo, dizem muito a respeito daquilo que se quer narrar, como se pretende narrar, e como se deseja que o protagonista seja visto. Em nosso caso, uma escolha se deu por exemplo em relação ao posicionamento da câmera na altura das pessoas sentadas nas calçadas.

No contexto urbano, nós andamos pelas calçadas e, consequentemente, miramos os moradores de rua do alto da nossa estatura. Enquanto circulamos, apressados, indo para o trabalho, voltando do mercado carregados de compras, ou simplesmente nos deslocando de um local para outro, temos uma relação de verticalidade. Frequentemente as pessoas em situação de rua nos veem de baixo para cima, enquanto nós as olhamos do alto, ou olhamos para a frente, ou para o nosso celular.

Rev. Eletrônica Mestr. Educ. Ambient. Rio Grande, Dossiê temático "Imagens: resistências e criações cotidianas", p.411-429, jun. 2020. E-ISSN 1517-1256 
Sentar-se na calçada, junto com nossos interlocutores, ou optar por posicionar a câmera na altura em que eles se encontram, nos permite escapar da relação de verticalidade para assumir tanto fisicamente como epistemicamente uma perspectiva de interlocução horizontal. Será essa uma das manifestações, da linha radical que, segundo Santos (2009), separa a existência da não-existência?

Para nós, a simples posição da câmera reafirmando uma relação de verticalidade, denunciaria a existência de uma sub-sociedade, escondida abaixo, onde quem está não é visto, não existe, e para onde miramos, do alto, como seres humanos melhores.

\section{4-3. Sobre trabalho, dignidade e ressignificações}

Aprendemos ao longo destes encontros que, embora nossos interlocutores parecessem estar desocupados, todos seguiam uma rotina rigorosa. Já contamos a rotina da Carla e seus netos, que vendem balas nos finais de semana.

Mas ainda é preciso contar que Bia, Fernanda, Paulo, Gloria e Alan também seguem uma rotina rígida: a hora de acordar para trabalhar no garimpo, catar no lixo os materiais recicláveis antes dos concorrentes e dos garis; a hora certa para chegar no depósito onde latinhas, papelões e outros frutos do garimpo são trocados por guloseimas e mercadorias para serem vendidas; a hora certa para aguardar no sinal os clientes apressados, para pegar água, para aguardar a distribuição de quentinhas, para tomar banho e voltar para o lar com segurança. Portanto, embora o sistema se negue a existencializar os moradores de rua, a enorme maioria deles trabalha, e colabora de forma silenciosa, eficiente e indispensável para compensar a insustentabilidade do universo do consumo, tão visível, sonoro e omnipresente nas mídias audiovisuais e no espaço urbano.

Observamos que essas pessoas passam a vida reafirmando sua dignidade. Isto pode ser notado na forma de ocupação dos espaços, ou na arrumação ordenada dos poucos pertences, ou ainda na distribuição equânime dos espaços numerados - para que todos tenham garantia de dimensões adequadas para instalar seu colchão.

A aspiração à dignidade da legalidade, da justiça social e de uma cidadania legitimada manifesta-se ainda, por exemplo, quando Glória guarda meticulosamente os documentos da família, ou quando Dona Carla organiza uma rotina semanal que parece insensata, até realizarmos que seu objetivo principal é garantir a educação dos netos.

A primeira fase de produção do documentário, a de gravação dos encontros, foi um período de muitas descobertas, deslocamentos de pontos-de-vista e desconstrução de 
certezas. Um período de desaprender asserções, aprendidas e assimiladas como verdades, mas que intuíamos como precisando ser urgentemente revistas. Mobilizados pela curiosidade e a surpresa das redescobertas que experimentamos, ao andentrarmos para o outro lado da linha da visibilidade, sentimos a urgência e a necessidade de se estabelecer um diálogo mais solidário com as pessoas de rua. Procuramos abraçar uma ética que implica em um olhar mais atento e uma escuta mais solidária, produtores de narrativas que não "falam sobre" mais que "dialogam com". Em um outro contexto, escrevemos que "quando investimos na produção científica em Educação como um campo de possibilidades e emergências, é possível encontrar zonas de identificação" (PASSOS, 2014, p. 240). São tais processos de identificação que buscamos destacar nessa narrativa, esperando que eles mobilizem também o leitor e, em breve, o espectador.

A segunda fase, a da montagem, está sendo criticamente impregnada e influenciada por tais processos. Mas, será apenas na terceira fase, a da projeção do produto final, que poderemos ter algumas respostas sobre nossa inquietação mobilizadora, que poderemos avaliar dialogicamente a extensão ou a limitação do processo ressignificação. Apenas os pesquisadores-alunos-produtores puderam ressignificar alguns dos seus conceitos, ou será que o mesmo também ocorreu para/com os protagonistas, os moradores de rua? Caso tenha ocorrido, qual foi a responsabilidade/participação/influência de cada "lado" nas transformações/ressignificações sofridas pelo "outro lado"? Pois afinal, ficamos cada um do seu lado da linha radical. Uma linha que, no processo, pode ter se deslocada para outra posição, menos superior, e/ou para outro ângulo, mais horizontal, separando agora em outro nível entre o existente de não-existente. Mas a linha não foi "apagada" pelo processo de produção audiovisual. Ao contrário, entendemos que a mudança mais profunda que ocorreu foi a evidenciação da própria linha, o que pode ser o primeiro passo para um diálogo mais solidário. Infelizmente, as condições atuais adiam nossos questionamentos e repostas.

\section{4-4. Um anexo circunstancial: Qual impacto da pandemia e do confinamento prolongado sobre a invisibilidade?}

Escrevemos este texto em meio à pandemia do COVID-19, uma tragédia sanitária que, através de um vírus microscópico propagado pelas nossas interações sociais, está assolando o planeta, com impactos de proporções nunca vistas antes neste século, e que já parecem escapar de controle na Cidade do Rio de Janeiro. Afastados dos nossos círculos de 
colaboradores, colegas e estudantes, restritos aos nossos respectivos espaços de confinamento, às nossas "casas", essa angústia que cresce em paralelo com as curvas das estatísticas de contaminação e mortes, não ameaça somente a nós e a nossos familiares, mas também aos protagonistas deste texto e do filme. Todos desapareceram dos seus espaços nas calçadas, dos seus pedaços de marquise, dos "endereços" que ocupavam há anos, e nos quais nós nos convidamos para as conversas.

Se foram removidos pelas autoridades e deslocados até centros de recolhimento, se pediram e conseguiram refúgio com algum conhecido, se foram afastados por hordas de novos desabrigados, se ficaram ou estão doentes, se receberam algum cuidado, não temos como saber, pois perdemos todo o contato com eles. Não há também como saber se, e quando, sairemos do isolamento social, a rua será a mesma. Muito provavelmente, "nada será como antes amanhã”, como compuseram Ronaldo Bastos e Milton Nascimento. Mas, então, como será?

Muito provavelmente, alguns protagonistas do documentário faltarão quando e se um dia - nós pudermos sair de nossas casas para assistir ao filme juntos, numa praça, transformada em efêmero cinema de rua, conforme tínhamos combinado, com o ânimo e a esperança de reunirmos todos os protagonistas ao escurecer de uma noite, na frente de um telão, Com certeza, nossa noite cinematográfica não será do jeito que sonhamos juntos.

As pessoas historicamente subalternizadas, desprovidas de legitimidade e de direitos, ficaram com uma missão: a de sobreviver à pandemia. De sobreviver em uma cidade maravilhosa e hoje fantasma, cujas praias e praças se esvaziaram. Sobreviver em um centro administrativo e comercial, outrora formigando de pessoas que os consideravam como leves ameaças anônimas ao seu bem estar. Mulheres, homens e crianças, cujo espaço de confinamento sempre foi a calçada. Pessoas que sempre foram consideradas como parte natural e inevitável do mobiliário de uma megalópole, ou como fiéis vendedores de balas e guloseimas. São populações vulneráveis que, mais do que nunca, foram agora esquecidas em situação de extremo abandono. Mais do que nunca, pessoas em situação de rua estão sendo ativamente apagadas do audiovisual cotidiano, num processo perverso através do qual estão sendo novamente e deliberadamente desumanizadas (SAKAMOTO, 2020)

Somam-se a estas, novas populações em grau de vulnerabilidade um pouco menor, mas não menos dramático. O país está "descobrindo" na pandemia números gigantescos de cidadãos contribuintes e eleitores, minimamente inseridos - formalmente ou não - na sociedade da produção, do consumo, da educação, da cultura, da arte. Cidadãos esses que vivem nas suas moradias e estavam "dando aquele jeito" para manterem suas famílias nos 
limites da dignidade, e se encontram hoje na beira de um colapso individual e existencial. Pois cada número, cada unidade das contas exponenciais e dos infográficos, é um indivíduo, uma pessoa com rosto, nome, laços afetivos, histórias, lutas, crenças e sonhos.

Vamos torcer para que surja do confinamento pandêmico um olhar renovado, menos arrogante e menos "superior" para com as pessoas que vivem nas calçadas, que reciclam nosso lixo e promovem a manutenção de um capitalismo insustentável, as que manipulam as caixas, empacotam e entregam nossa comida, que dirigem e que descarregam na madrugada carretas de mantimentos e verduras frescas. As pessoas, anonimizadas pelos uniformes das empresas que asseguram a manutenção das nossas redes de eletricidade, gás, água, telefonia e internet, graças as quais podemos assistir a mais uma aula ou a mais um filme. Essa é nossa esperança, nosso desejo, que temos alimentado desde a captura das primeiras imagens e que cresceu nas encruzilhadas desta narrativa préedição do filme: que cada ser humano, sobrevivente, possa sair do isolamento social com um olhar renovado, seja para apontar a objetiva de uma câmera digital, cujas imagens serão editadas, encenadas, projetadas e possivelmente transmitidas em mundovisão, ou seja "apenas" para apontar seu olhar pessoal e intimo sobre o mundo.

Pois é, também, a partir das imagens dos mundos exteriores que elaboramos nossos mundos interiores. Nunca vivenciamos, em tal escala espaço-temporal planetária, uma situação de múltiplos estresses prolongados, por uma duração que, aliás, ainda ignoramos. À medida em que aumentam as dimensões das saudades e o peso das notícias, seguimos ressignificando nossos conceitos de lar, família, amigo, vizinho, comunidade, cidadania, desigualdade, distância afetiva.

Em confinamento, nossa mente se alimenta dos múltiplos sinais audiovisuais disponíveis, mas nosso corpo está preso nas paredes da nossa casa. Durante meses de angústia e de privação de contato físico além da nossa micro-comunidade de confinamento, sofreremos profundas alterações cognitivas e morais. A pandemia do "novo" coronavírus não é democrática. Mas, de certa forma, ela é fundamentalmente igualitária: para este vírus, cada pessoa tem sua existência legitimada, como potencial alvo para ser infectado. E a única medida preventiva é o distanciamento.

Esperamos que, quando finalmente dispensáveis, as máscaras cairão, abaixaremos também nossos olhares daquela perspectiva normatizante e conformada. Seremos capazes de abrir nosso ângulo de visão, de reajustar nossa distância focal e social, para aprendemos a significar o termo "desdistanciamento"? 


\section{Referências}

BAKHTIN, Mikhail. Problemas da poética de Dostoievski. Tradução Paulo Bezerra. $4^{\mathrm{a}}$ Edição. Rio de Janeiro: Forense Universitária, 2008.

BHABHA, Homi. O local da cultura. Tradução Myriam Ávila. Belo Horizonte, Editora UFMG: 1998.

CERTEAU, Michel. A invenção do Cotidiano: Artes de fazer. Tradução Ephraim Ferreira Alves. Petrópolis, Editora Vozes: 1994.

FANON. Frantz. Pele negra, máscaras brancas. Tradução Renato da Silveira. Salvador: EDUFBA, 2008

PASSOS, Mailsa Carla P. Encontros cotidianos e a pesquisa em Educação: relações raciais, experiência dialógica e processos de identificação. Educar em Revista, Curitiba, v. 30, n. 51, p. 227-242, 2014.

PEIXOTO, Clarice, Ehles (org.) Antropologia e imagem - narrativas diversas. Rio de Janeiro: Editora Garamont/FAPERJ, 2011.

SAKAMOTO, L (2020). "Coronavírus: Brasil mostra que é projetado para matar pobre em pandemia”. (2020-05-07, UOL Noticias. Disponível em:

https://noticias.uol.com.br/colunas/leonardo-sakamoto/2020/05/06/coronavirus-brasilmostra-que-e-projetado-para-matar-pobre-em-pandemia.htm. Acesso em: 07 maio 2020. SANTOS, Boaventura de Sousa \& MENESES, Maria Paula. Epistemologias do Sul. São Paulo, Cortez: 2010.

AGRADECIMENTOS: Agradecemos a todos as pessoas que contribuíram ativamente e subjetivamente com o projeto "Endereço": Os protagonistas: Alan, Bia, Carla, Glória, Paulo e as crianças Alana, Alanzinho, Robson e Tatá. A cinegrafista Fátima Rodrigues. Os estudantes Carol, Danielle, Irani, Geoésley, Loranne, Luciane, Perseu, Rizza, Ronaldo, Rosimeri, Walter, Kennel. Os parceiros Iris, Virgínia, Lau, Regina, Rita, Marcela. Os agentes dos serviços sociais e jurídicos e os inúmeros anônimos que, de uma forma ou de outra, ensinaram a equipe a renovar seu olhar. À FAPERJ e à UERJ pelo apoio financeiro.

Submetido em: 11-05-2020.

Publicado em: 01-07-2020.

Rev. Eletrônica Mestr. Educ. Ambient. Rio Grande, Dossiê temático "Imagens: resistências e criações cotidianas”, p.411-429, jun. 2020. E-ISSN 1517-1256 